\title{
Dynamic Analysis and Optimization of the Planar Model of the Trolleybus Škoda 21Tr
}

Stefan Segl'a ${ }^{1}$, Jan Kampo², Josef Soukup ${ }^{2}$

${ }^{1}$ Faculty of Mechanical Engineering, TU in Košice, Letná 9, 04200 Košice, e-mail: stefan.segla@tuke.sk

${ }^{2}$ Faculty of Mechanical Engineering, J. E. Purkyne University in Usti nad Labem, Pasteurova 3334/7, 400 96 Ústí nad

Labem, jan.kampo@ujep.cz, josef.soukup@ujep.cz

The article deals about modelling, dynamic analysis and optimization of stiffness and damping parameters of the main suspension of the Š koda 21 Tr trolleybus. The trolleybus is excited by a ride on a rough road modelled using the Shinozuka method with the specified spectral power density. After examining the impact of tire stiffness and damping on the effective values of driving comfort characteristics, dynamic tire-to-road forces, and relative displacements between sprung and unsprang mass, the effect of spring stiffness and damping of dampers in main suspension are investigated. After selecting appropriate optimization parameters, the stiffness and damping parameters of the main suspension are optimized using the MATLAB Optimization Toolbox. The objective function is the sum of the effective values of the suspension mass acceleration and its angular acceleration. The results are the improved driving comfort without increasing the dynamic forces between the tires and the road and the relative displacements between the sprung and unsprung masses.

Keywords: Road, Modelling, Vehicle dynamics, Optimization, Stochastic excitation

\section{Introduction}

The basic task of the vehicle suspension is to ensure the suspension vehicle ride comfort, minimizing the dynamic forces between tires and the road and workspace suspension as shown for example in Andrzejewski and Awrejcewicz [1], Segla and Kampo [6], Segla and Reich [7], and Sekulic et al. [8]. In the case of the Škoda 21Tr trolleybus, this is a passive suspension with cylindrical springs and hydraulic dampers, the parameters of which are given in Volek et al. [9], including mass and geometrical parameters.

The aims of the article are to analyze the geometrical characteristics of the trolleybus when driving on a stochastically uneven road, to investigate the influence of important parameters and to find out the possibilities of improving the comfort of the ride while preserving the suspension working space and not increasing the level of dynamic forces between the tires and the road.

The advantages of the planar model used are to increase the clarity of the impact of the individual suspension parameters and considerably less time needed for optimization using genetic algorithms in the MATLAB programming environment.

\section{Dynamic and mathematical model of trolley- bus}

Fig. 1 illustrates the planar dynamic model of the investigated trolleybus. Its mass, damping, stiffness and geometrical parameters are given in chap. 3 and 4. Differences in results due to mass asymmetry (eccentricity of the centre of gravity of the trolleybus, as well as asymmetrical stiffness of the springs on the left and right side of the vehicle) can be expected in comparison to the spatial model solution.

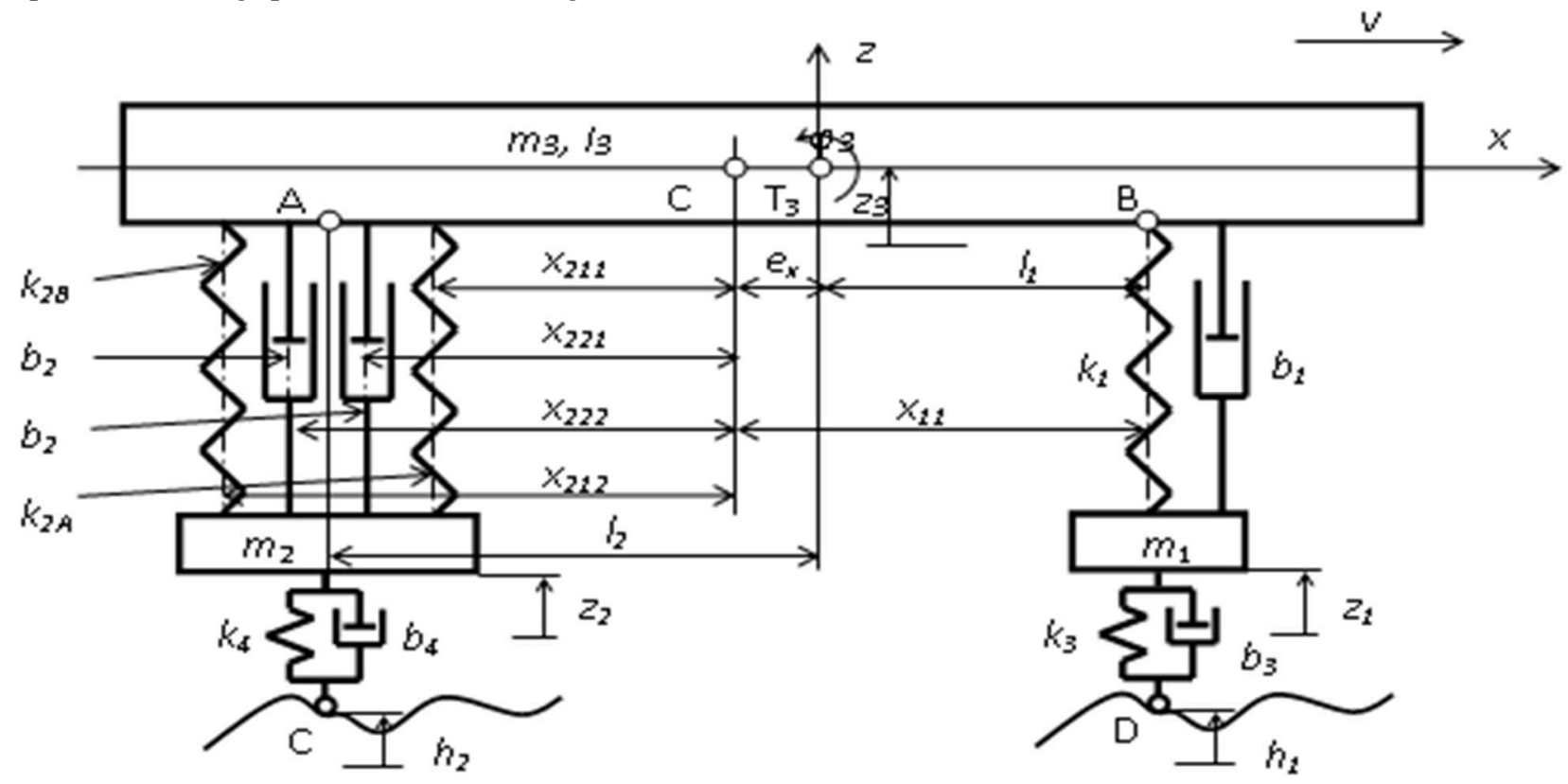

Fig. 1 Flat model of the trolleybus Škoda $21 \mathrm{Tr}$ 
Motion equations are

$$
\begin{aligned}
& m_{1} \ddot{z}_{1}+b_{3}\left(\dot{z}_{1}-\dot{h}_{1}\right)-b_{1}\left[\dot{z}_{3}+\left(x_{12}-e_{X}\right) \dot{\varphi}_{3}-\dot{z}_{1}\right]+k_{3}\left(z_{1}-h_{1}\right)- \\
& -k_{1}\left[z_{3}+\left(x_{11}-e_{X}\right) \varphi_{3}-z_{1}\right]=0 \text {, } \\
& m_{2} \ddot{z}_{2}+b_{4}\left(\dot{z}_{2}-\dot{h}_{2}\right)-b_{2 A}\left[\dot{z}_{3}-\left(x_{221}+e_{x}\right) \dot{\varphi}_{3}-\dot{z}_{2}\right]-b_{2 B}\left[\dot{z}_{3}-\left(x_{222}+e_{x}\right) \dot{\varphi}_{3}-\dot{z}_{2}\right]+ \\
& +k_{4}\left(z_{2}-h_{2}\right)-k_{2 A}\left[z_{3}-\left(x_{211}+e_{x}\right) \varphi_{3}-z_{2}\right]-k_{2 B}\left[z_{3}-\left(x_{212}+e_{x}\right) \varphi_{3}-z_{2}\right]=0, \\
& m_{3} \ddot{z}_{3}+b_{1}\left[\dot{z}_{3}-\left(x_{11}-e_{x}\right) \dot{\varphi}_{3}-\dot{z}_{1}\right]+b_{2 A}\left[\dot{z}_{3}-\left(x_{221}+e_{x}\right) \dot{\varphi}_{3}-\dot{z}_{2}\right]+ \\
& +b_{2 B}\left[\dot{z}_{3}-\left(x_{222}+e_{X}\right) \dot{\varphi}_{3}-\dot{z}_{2}\right]+k_{1}\left[z_{3}+\left(x_{11}-e_{X}\right) \varphi_{3}-z_{1}\right]+ \\
& +k_{2 A}\left[z_{3}-\left(x_{211}+e_{X}\right) \varphi_{3}-z_{2}\right]+k_{2 B}\left[z_{3}-\left(x_{212}+e_{X}\right) \varphi_{3}-z_{2}\right]=0, \\
& I_{3} \ddot{\varphi}_{3}+b_{1}\left(x_{12}-e_{x}\right)\left[\dot{z}_{3}-\left(x_{12}-e_{X}\right) \dot{\varphi}_{3}-\dot{z}_{1}\right]-b_{2 A}\left(x_{221}+e_{X}\right) \text {. } \\
& \cdot\left[\dot{z}_{3}-\left(x_{221}+e_{x}\right) \dot{\varphi}_{3}-\dot{z}_{2}\right]-b_{2 B}\left(x_{222}+e_{x}\right) \text {. } \\
& \cdot\left[\dot{z}_{3}-\left(x_{221}+e_{x}\right) \dot{\varphi}_{3}-\dot{z}_{2}\right]+k_{1}\left(x_{11}-e_{x}\right)\left[z_{3}+\left(x_{11}-e_{x}\right) \varphi_{3}-z_{1}\right]+ \\
& -k_{2 A}\left(x_{211}+e_{X}\right)\left[z_{3}-\left(x_{211}+e_{X}\right) \varphi_{3}-z_{2}\right]- \\
& -k_{2 B}\left(x_{212}+e_{X}\right)\left[z_{3}-\left(x_{221}+e_{X}\right) \varphi_{3}-z_{2}\right]=0 \text {. }
\end{aligned}
$$

For solution in the MATLAB program environment, this set of the second order ordinary differential equations

$$
y_{1}=\dot{z}_{1}, \quad y_{2}=z_{1}, \quad y_{3}=\dot{z}_{2}, \quad y_{4}=z_{2}, \quad y_{5}=\dot{z}_{3}, \quad y_{6}=z_{3} \quad y_{7}=\dot{\varphi}_{3}, \quad y_{8}=\varphi_{3} .
$$

(ODR) is transformed into the first order ODR system by coordinate transformation

The dynamic forces between the tires and the road expressed for clarity using the original coordinates are

$$
F_{d y n, D}=k_{3}\left(z_{1}-h_{1}\right)+b_{3}\left(\dot{z}_{1}-\dot{h}_{1}\right), \quad F_{d y n, C}=k_{4}\left(z_{2}-h_{2}\right)+b_{4}\left(\dot{z}_{2}-\dot{h}_{2}\right),
$$

where $h_{1}, h_{2}$ are road unevennesses generated by the Shinozuka method described in Nigam and Narayanan [3].

The relative displacement between the point $\mathrm{B}$ of the sprung mass $m_{3}$ and the unsprung mass $m_{1}$ is

$$
z_{\text {rel,B }}=z_{3}+l_{1} \varphi_{3}-z_{1}
$$

and between the point $\mathrm{A}$ of the sprung mass $m_{3}$ and the unsprung mass $m_{2}$ is

$$
z_{r e l, A}=z_{3}-l_{2} \varphi_{3}-z_{2} \text {. }
$$

\section{Dynamic analysis}

Consider the trolleybus simulation at a speed of 50 $\mathrm{km} / \mathrm{h}$ in a time interval from $0 \mathrm{~s}$ to $T=20 \mathrm{~s}$. The stochastic pathway generated by the Shinozuka method for the "good" asphalt-concrete road illustrates Fig. 2.

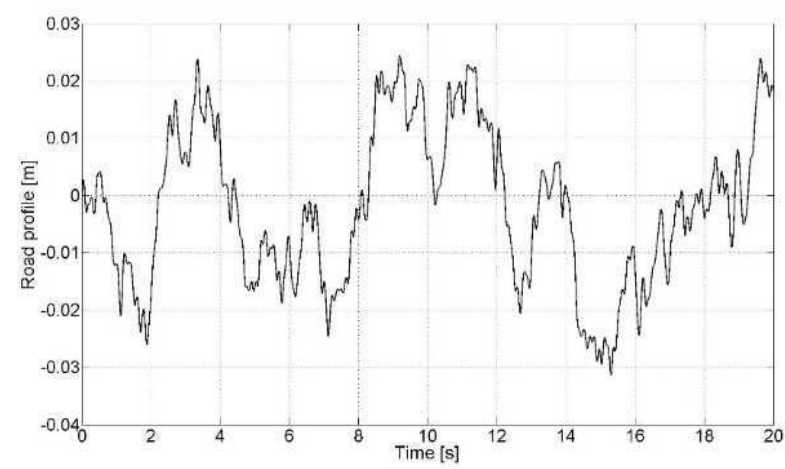

Fig. 2. The profil of a "good" asphalt-concrete road with the power spectral density $S_{h}\left(\Omega_{0}\right)=6.10-6 \mathrm{~m}^{3}$.
It is obvious that the comfort of the ride can be increased mainly by decreasing the stiffness of the springs in the main suspension, therefore the stiffnesses of the front and rear springs will be further considered according to Tab. 1. In the first row the stiffnesses are original, in each other they are reduced by $10 \%$.

Tab. 1 Stiffness of the main springs

\begin{tabular}{|c|c|c|}
\hline $\begin{array}{c}\text { Combination of stiffness } \\
\mathrm{A}_{i}, \mathrm{~B}_{i}\end{array}$ & $k_{1}[\mathrm{~N} / \mathrm{m}]$ & $k_{2 \mathrm{~A}}[\mathrm{~N} / \mathrm{m}]$ \\
\hline $\mathrm{A}_{1}, \mathrm{~B}_{1}$ & 290250.0 & 186836.0 \\
\hline $\mathrm{A}_{2}, \mathrm{~B}_{2}$ & 275375.5 & 177494.0 \\
\hline $\mathrm{A}_{3}, \mathrm{~B}_{3}$ & 261225.0 & 168153.0 \\
\hline $\mathrm{A}_{4}, \mathrm{~B}_{4}$ & 246712.5 & 158811.0 \\
\hline $\mathrm{A}_{5}, \mathrm{~B}_{5}$ & 232200.0 & 149470.0 \\
\hline
\end{tabular}

Numerical dynamic analysis will investigate the effective values (EV) of the following variables: $\ddot{z}_{T, e f}-\mathrm{EV}$ of the vertical acceleration of the center of gravity $T_{3}$ of the sprung mass $m_{3}, \ddot{\varphi}_{3, \text { ef }}$ - EV of the angular acceleration of the sprung mass $m_{3}, \ddot{z}_{\mathrm{A}, \text { ef }}-\mathrm{EV}$ of the vertical acceleration of point A of the sprung mass $m_{3}, \ddot{z}_{\mathrm{B}, e f}-\mathrm{EV}$ of the vertical acceleration of the point $B$ of the sprung mass $m_{3}, f_{D_{d y n, e f}}-\mathrm{EV}$ of the dynamic force between the tires and road (point D, rear axle), $f_{C_{d y n, e f}}-\mathrm{EV}$ of the dynamic force between the tires and road (point $\mathrm{C}$, front axle), $\left(z_{\mathrm{B}}-z_{1}\right)_{e f}$ - EV of the relative displacement between the point $\mathrm{B}$ of the sprung mass $m_{3}$ and unsprung mass $m_{1}$, $\left(z_{\mathrm{A}}-z_{2}\right)_{e f}-\mathrm{EV}$ of the relative displacement between the 
point A of the sprung mass $m_{3}$ a unsprung mass $m_{2}$.

Total EV acceleration $\ddot{z}_{T, e f}$ and $\ddot{\varphi}_{3, e f}$ determines driving comfort, so it will later be used as the objective function for optimizing the main suspension parameters.

For combinations of stiffness $\mathrm{A}_{i}, \mathrm{~B}_{i}$ from Tab. 1 (A determines the stiffness value $k_{l}$, B the stiffness value $k_{2 A}$ and $i$ determines the line number) the analysis results are shown in Tab. 2. The EV of all variables are computed from time $T=2 \mathrm{~s}$ to $T=20 \mathrm{~s}$ to eliminate transition phenomena at start of the ride of the trolleybus.

Tab. 2 a Influence of the main suspension on the effective values of quantities

\begin{tabular}{|c|c|c|c|c|c|}
\hline $\begin{array}{c}\text { Combination of } \\
\text { stiffness } \mathrm{A}_{i}, \mathrm{~B}_{i}\end{array}$ & $\ddot{z}_{T, e f}+\ddot{\varphi}_{3, \text { ef }}$ & $\ddot{z}_{T, \text { ef }}$ & $\ddot{z}_{A, \text { ef }}$ & $\ddot{z}_{B, \text { ef }}$ & $\ddot{\varphi}_{3, \text { ef }}$ \\
\hline $\mathrm{A}_{1}, \mathrm{~B}_{1}$ & 0.664472 & 0.498262 & 0.688187 & 0.686474 & 0.166211 \\
\hline $\mathrm{A}_{2}, \mathrm{~B}_{2}$ & 0.665863 & 0.500342 & 0.667090 & 0.700132 & 0.165520 \\
\hline $\mathrm{A}_{3}, \mathrm{~B}_{3}$ & 0.665893 & 0.502854 & 0.644703 & 0.708586 & 0.163039 \\
\hline $\mathrm{A}_{4}, \mathrm{~B}_{4}$ & 0.644634 & 0.490559 & 0.620986 & 0.680379 & 0.154074 \\
\hline $\mathrm{A}_{5}, \mathrm{~B}_{5}$ & 0.598200 & 0.459405 & 0.597761 & 0.610332 & 0.138795 \\
\hline
\end{tabular}

Tab. $2 \boldsymbol{b}$ Influence of the main suspension stiffnesses on the effective values of quantities (continued)

\begin{tabular}{|c|c|c|c|c|}
\hline $\begin{array}{c}\text { Combination of } \\
\text { stiffness } A_{\mathrm{i},}, B_{\mathrm{i}}\end{array}$ & $f_{\text {Cdyn,ef }}$ & $f_{\text {Ddyn,ef }}$ & $\left(z_{B}-z_{1}\right)_{\text {ef }}$ & $\left(z_{A}-z_{2}\right)_{\text {ef }}$ \\
\hline$A_{1}, B_{1}$ & 4033.58 & 4170.04 & 0.014099 & 0.005956 \\
\hline$A_{2}, B_{2}$ & 4015.73 & 4256.42 & 0.015140 & 0.005998 \\
\hline$A_{3}, B_{3}$ & 3991.67 & 4303.54 & 0.016118 & 0.005983 \\
\hline$A_{4}, B_{4}$ & 3957.37 & 4118.31 & 0.016312 & 0.005837 \\
\hline$A_{5}, B_{5}$ & 3922.55 & 3674.11 & 0.015429 & 0.005581 \\
\hline
\end{tabular}

With decreasing the stiffness of the suspension the sum $\ddot{z}_{T, e f}+\ddot{\varphi}_{3, e f}$ (initially slightly growing) decreases and consequently also driving comfort decreases. However, the reduction in the stiffness of the main suspension is limited by other factors - mainly by changing the vertical position of the sprung mass $m_{3}$ at the static load of the trolleybus by its own weight. Furthermore, it is interesting that the effective value of the dynamic force between the tires and the road under the front axle $f_{D_{\text {dyn }, e f}}$ after the initial slight increase later significantly decreases. Conversely beneath the rear axle the force from the start is declining very little. EV of the relative displacement between $\mathrm{B}$ and the mass $m_{1}$ first increased and later declined. EV of the relative displacement between point $\mathrm{A}$ and the mass $m_{2}$ first slightly increased and later declined. From the driving comfort point of view EV of the vertical acceleration of points $\mathrm{A}$ and $\mathrm{B}$ of the rear and front axle is also important. EV of the acceleration of point A still decreases, while in point $B$ after a slight increase later decreases also relatively significantly.

Tab. 3 illustrates the possibility of neglecting tire damping, which is often done in literature. The first row of Tab. 3 shows the results for the intended tire damping and the second with its neglect. Differences of EV of all monitored quantities are practically negligible.

Tab. 3 a Effect of tire damping

\begin{tabular}{|c|c|c|c|c|c|}
\hline Damping of tires & $\ddot{z}_{T, e f}+\ddot{\varphi}_{3, e f}$ & $\ddot{z}_{T, e f}$ & $\ddot{z}_{A, e f}$ & $\ddot{z}_{B, e f}$ & $\ddot{\varphi}_{3, e f}$ \\
\hline Original (nonzero) & 0.664472 & 0.498262 & 0.688187 & 0.686474 & 0.166211 \\
\hline 0 & 0.678249 & 0.508782 & 0.688419 & 0.708730 & 0.169467 \\
\hline
\end{tabular}

Tab. $3 \boldsymbol{b}$ Effect of tire damping (continued)

\begin{tabular}{|c|c|c|c|c|}
\hline Damping of tires & $f_{C d y n, e f}$ & $f_{\text {Ddyn,ef }}$ & $\left(z_{B}-z_{1}\right)_{e f}$ & $\left(z_{A}-z_{2}\right)_{e f}$ \\
\hline Original (nonzero) & 4490.870000 & 4170.040000 & 0.014100 & 0.005956 \\
\hline 0 & 4521.180000 & 4315.830000 & 0.014558 & 0.005951 \\
\hline
\end{tabular}

Tab. 3 shows, that the influence of tire damping is practically negligible for all the measured quantities.

The influence of tire stiffness is shown in Tab. 4, where the stiffness of the tires decreases by 10 percent of the original values. It is clear from the results that the tire stiffness leads to a smaller increase in the EV of the measured values, except for the EV of the acceleration above the rear axle where there is a slight decrease.

Tab. 4 a Influence of tire stiffness

\begin{tabular}{|c|c|c|c|c|c|}
\hline Stiffnesses of tires & $\ddot{z}_{T, e f}+\ddot{\varphi}_{3, \text { ef }}$ & $\ddot{z}_{T, \text { ef }}$ & $\ddot{z}_{A, \text { ef }}$ & $\ddot{z}_{B, e f}$ & $\ddot{\varphi}_{3, \text { ef }}$ \\
\hline Original stiffness & 0.664472 & 0.498262 & 0.688187 & 0.686474 & 0.166211 \\
\hline Decrease by $10 \%$ & 0.671417 & 0.503768 & 0.686575 & 0.698735 & 0.167648 \\
\hline Decrease by $20 \%$ & 0.681372 & 0.511628 & 0.682159 & 0.717422 & 0.169744 \\
\hline
\end{tabular}


Tab. $4 \boldsymbol{b}$ Influence of tire stiffness (continued)

\begin{tabular}{|c|c|c|c|c|}
\hline Stiffnesses of tires & $f_{\text {Cdyn,ef }}$ & $f_{\text {Ddyn,ef }}$ & $\left(z_{B}-z_{1}\right)_{e f}$ & $\left(z_{A}-z_{2}\right)_{e f}$ \\
\hline Original stiffness & 4490.870000 & 4170.040000 & 0.014100 & 0.005956 \\
\hline Decrease by $10 \%$ & 4514.230000 & 4249.630000 & 0.014347 & 0.005987 \\
\hline Decrease by $20 \%$ & 4721.980000 & 4369.290000 & 0.014729 & 0.006023 \\
\hline
\end{tabular}

Tab. 5 shows the effect of damping in the main suspension. The stiffness in it is original. Damping coefficient values decrease gradually by $10 \%$ to $40 \%$ in the last row. It is clear from the results that increasing damping reduces driving comfort. Above the rear axle, this reduction is insignificant, but the front axle is more pronounced. The dynamic force between the tires and the road grows below both axles, similarly the relative displacements between the sprung and unsprung masses.

Tab. 5a Influence of damping in the main suspension

\begin{tabular}{|c|c|c|c|c|c|}
\hline Damping & $\ddot{z}_{T, e f}+\ddot{\varphi}_{3, e f}$ & $\ddot{z}_{T, e f}$ & $\ddot{z}_{A, e f}$ & $\ddot{z}_{B, e f}$ & $\ddot{\varphi}_{3, e f}$ \\
\hline Original damping & 0.664472 & 0.498262 & 0.688187 & 0.686474 & 0.166211 \\
\hline$-10 \%$ & 0.679222 & 0.508979 & 0.682978 & 0.715144 & 0.170243 \\
\hline$-20 \%$ & 0.698811 & 0.523417 & 0.683555 & 0.747758 & 0.175395 \\
\hline$-30 \%$ & 0.722405 & 0.542558 & 0.692197 & 0.785214 & 0.181948 \\
\hline$-40 \%$ & 0.758242 & 0.567915 & 0.712408 & 0.828870 & 0.190326 \\
\hline
\end{tabular}

Tab. $5 \boldsymbol{b}$ Influence of damping in the main suspension (continued)

\begin{tabular}{|c|c|c|c|c|}
\hline Damping & $f_{\text {Cdyn,ef }}$ & $f_{\text {Ddyn,ef }}$ & $\left(z_{B}-z_{1}\right)_{\text {ef }}$ & $\left(z_{A}-z_{2}\right)_{e f}$ \\
\hline Original damping & 4490.87 & 4170.04 & 0.14100 & 0.005956 \\
\hline$-10 \%$ & 4626.16 & 4352.18 & 0.114752 & 0.006239 \\
\hline$-20 \%$ & 4834.15 & 4558.14 & 0.015483 & 0.006571 \\
\hline$-30 \%$ & 5013.16 & 4793.26 & 0.016309 & 0.006973 \\
\hline$-40 \%$ & 5260.81 & 5065.54 & 0.017259 & 0.007473 \\
\hline
\end{tabular}

\section{Optimization}

The results of the numerical analyzes from the previous chapter lead to the following selection of optimization parameters: $k_{1}$ - spring stiffness coefficient in the front main suspension (Fig. 1), $k_{2 \mathrm{~A}}$ - stiffness coefficient of the front springs in the rear main suspension. The stiffness coefficient of the rear springs is $k_{2 \mathrm{~B}}=k_{2 \mathrm{~A}}, b_{1}$ - damping coefficient in the front main suspension, $b_{2 \mathrm{~A}}-$ damping coefficient of the front dampers in the rear main suspension. The stifness coefficient of the rear dampers is $k_{2 \mathrm{~B}}$ $=k_{2 \mathrm{~A}}$.

The trolleybus mass parameters are: $m_{1}=466.26000$ $\mathrm{kg}, m_{2}=1489.20000 \mathrm{~kg}, m_{3}=8697.00000 \mathrm{~kg}, I_{3}=$ $99287.16400 \mathrm{~kg} \cdot \mathrm{m}^{2}$. Coefficients of damping: $b_{1}=$ $6684.49200 \mathrm{Ns} / \mathrm{m}, b_{2 \mathrm{~A}}=b_{2 \mathrm{~B}}=11268.14360 \mathrm{Ns} / \mathrm{m}$. Stiffnesses of springs: $k_{1}=290250.00000 \mathrm{~N} / \mathrm{m}, k_{2 \mathrm{~A}}=k_{2 \mathrm{~B}}=$ $186836.80000 \mathrm{~N} / \mathrm{m}$. Tire damping coefficients: $b_{3}=$ $15267.50000 \mathrm{Ns} / \mathrm{m}, b_{4}=30535.00000 \mathrm{Ns} / \mathrm{m}$. Tire stiffness coefficients: $k_{3}=1970000.00000 \mathrm{~N} / \mathrm{m}, k_{4}=$ $3940000.00000 \mathrm{~N} / \mathrm{m}$. Geometrical parameters: $x_{11}=$ $3.06000 \mathrm{~m}, x_{12}=3.07800 \mathrm{~m}, x_{211}=2.12500 \mathrm{~m}, x_{221}=$ $2.24000 \mathrm{~m}, x_{212}=3.57500 \mathrm{~m}, x_{222}=3.46000 \mathrm{~m}, l_{1}=$ $2.26382 \mathrm{~m}, l_{2}=3.85618 \mathrm{~m}, e_{x}=0.79618 \mathrm{~m}$ (excentricity of the center of gravity $T_{3}$ ).

The search intervals are: $k_{1} \in\langle 232200290250\rangle \mathrm{N} / \mathrm{m}$, $k_{2} \in\langle 149470186836\rangle \mathrm{N} / \mathrm{m}, \quad b_{1} \in\langle 55008500\rangle \mathrm{Ns} / \mathrm{m}$, $b_{2 \mathrm{~A}} \in\langle 300012000\rangle \mathrm{Ns} / \mathrm{m}$.

The optimization algorithms of the Matlab Optimization Toolbox [2] were used.
As the objective function, the sum of the effective values of the vertical acceleration of the sprung mass and the angular acceleration of the sprung mass was used as can be found in Rao [4] and Segla [5].

The optimal parameters are: $k_{1, \text { opt }}=232200.000000$ $\mathrm{N} / \mathrm{m}, k_{2 \mathrm{~A}, \text { opt }}=149470.000000 \mathrm{~N} / \mathrm{m}, b_{1, \text { opt }}=7899.350000$ $\mathrm{Ns} / \mathrm{m}, b_{2 \mathrm{~A}, \text { opt }}=7010.000000 \mathrm{Ns} / \mathrm{m}$. The objective function value is $f_{\text {opt }}=0.501453$. Compared with the results in Tab. 2 it can be found that considering the damping coefficients as further optimization parameters has further improved the comfort of trolleybus driving at a given stiffness interval.

Fig. 3 illustrates the acceleration course of the sprung mass after optimization of the main suspension parameters. Fig. 4 shows the dynamic force between the tire and the road under the front axle.

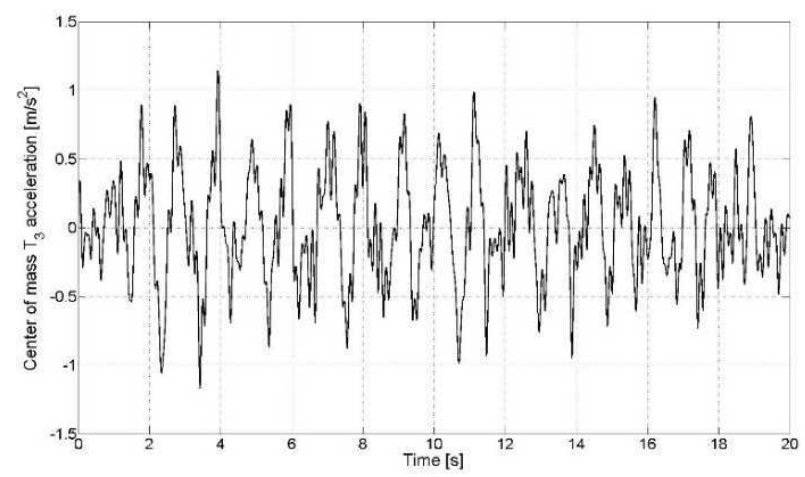

Fig. 3 Acceleration of the sprung mass center of gravity. 


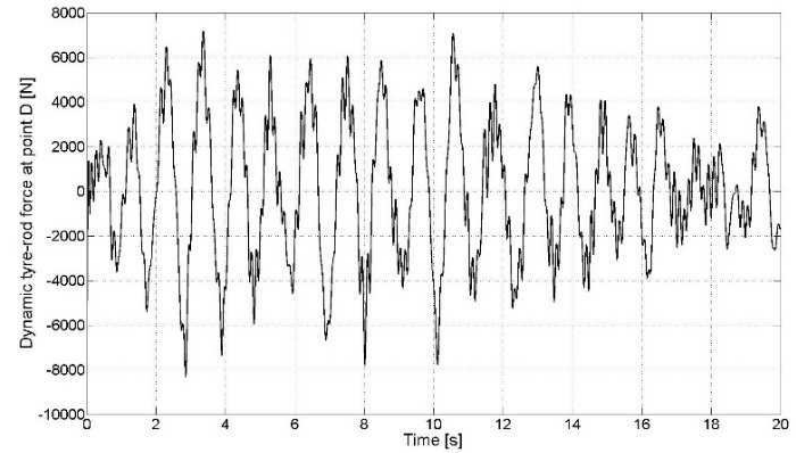

Fig. 4 Dynamic force between the tire and the road under the front axle

For optimal values of optimization variables, the EVs of the monitored variables are: $\ddot{z}_{T, \text { ef }}=0.400368 \mathrm{~m} / \mathrm{s}^{2}$, $\ddot{\varphi}_{3, e f}=0.101085 \mathrm{rad} / \mathrm{s}^{2}, \ddot{z}_{\mathrm{A}, e f}=0.561269 \mathrm{~m} / \mathrm{s}^{2}, \ddot{z}_{\mathrm{B}, \text { ef }}=$ $0.507605 \mathrm{~m} / \mathrm{s}^{2}, f_{C_{\text {dyn,ef }}}=3873.050000 \mathrm{~N}, f_{D_{\text {dyn,ef }}}=$ $3046.910000 \mathrm{~N},\left(z_{\mathrm{B}}-z_{1}\right)_{e f}=0.012652 \mathrm{~m},\left(z_{\mathrm{A}}-z_{2}\right)_{e f}=$ $0.006443 \mathrm{~m}$.

By comparing these values with the values in the first row of Tab. 2 (original parameters of the trolleybus) shows that, in addition to a relatively significant improvement in driving comfort, there was also a slight decrease in the EV of the dynamic force between the rear tires and the road, a significant reduction in the EV of the dynamic force between the front tires and the road, a slight decrease in the relative displacement $\operatorname{EV}\left(z_{\mathrm{A}}-z_{2}\right)_{\text {ef }}$ and a negligible increase in EV of the relative displacement $\left(z_{\mathrm{B}}\right.$ $\left.-z_{1}\right)_{e f}$. These results confirm that in this case it was not necessary to use constraints on the EV of the dynamic forces between the tires and the road and the EV of the relative displacements affecting the suspension working space.

\section{Conclusion}

The article presents the possibilities of improving the ride comfort of the Škoda 21Trolleybus. After the dynamical analysis of the influence of stiffness coefficients and the damping of the main suspension and tires, the optimization of selected stiffness and damping parameters of the planar model was performed.

The optimization results show a relatively significant increase in the ride comfort with a slight reduction in the $\mathrm{EV}$ of the dynamic force between the rear tires and the road, a significant reduction in the EV of the dynamic force between the front tires and the road, and the maintenance of the $\mathrm{EV}$ of the relative displacements between the sprung and unsprung masses on the front and rear axles.

\section{Acknowledgments}

The article has been supported by grant project VEGA No. $1 / 0290 / 18$.

\section{References}

[1] ANDRZEJEWSKI, J., AWREJCEWICZ, J., (2005). Nonlinear dynamics of a wheeled vehicle. Springer, New York, 2005.

[2] Genetic Algorithm and Direct Search Toolbox User's Guide (2004). The Mathworks Inc., Natick, 2004.

[3] NIGAM, N. C., NARAYANAN, S., (1994). Applications of Random Vibrations. Springer -Verlag, New York, 1994.

[4] RAO, S.S., (1996). Engineering Optimization. Theory and Practice. John Wiley \& Sons, New York, 1996.

[5] SEGLA, S., (2018). Kinematic analysis and optimization of a wheel loader mechanism. Manufacturing Technology, vol. 18, 2018, pp. 309-314.

[6] SEGLA, S., KAMPO, J., (2018). The role of modelling of road unevenness in vehicle dynamics. Manufacturing Technology, vol. 18, 2018, pp. 124-129.

[7] SEGLA, S., REICH, S., (2007). Optimization and comparison of passive, active, and semi-active vehicle suspension systems. In: Proceedings of the 12th IFToMM World Congress on Mechanism Science, Besancon (France), 2007.

[8] SEKUliC, D., DEDOVIC, V., RUSOV, S., SALINIC, S., OBRADOVIC, A., (2013). Analysis of vibration effects on the comfort of intercity bus users by oscillatory model with ten degrees of freedom. Applied Mathematical Modelling, vol. 37, 2013, pp. 8629-8644.

[9] VOLEK, J., SEGLA, S., SOUKUP, J., (2007). Analytický výpočet vertikálních posuvů trolejbusu Škoda 21 Tr při přejezdu soustavy překážek dle ČSN ve stanovených bodech. Výzkumná zpráva č. 05/07, FVTM UJEP v Ústí nad Labem, 2007. 